\title{
Extension of the Frontiers of Surgical Indications in the Treatment of Liver Metastases From Colorectal Cancer
}

\author{
Long-Term Results
}

\author{
Masami Minagawa, MD, ${ }^{\star}$ Masatoshi Makuuchi, MD, ${ }^{\star}$ Guido Torzilli, MD, ${ }^{*}$ Tadatoshi Takayama, MD, ${ }^{\star}$ Seiji Kawasaki, MD, $†$ \\ Tomoo Kosuge, MD, $\ddagger$ Junji Yamamoto, MD, $\ddagger$ and Hiroshi Imamura, MD*
}

From the *Department of Hepato-Biliary-Pancreatic Surgery, the Department of Artificial Organ and Transplantation, Graduate School of Medicine, University of Tokyo, Tokyo, Japan; the †First Department of Surgery, Shinshu University, Matsumoto, Japan; and the $\ddagger$ Department of Surgery, National Cancer Center, Tokyo, Japan

\section{Objective}

To evaluate retrospectively the long-term results of an approach consisting of performing surgery in every patient in whom radical removal of all metastatic disease was technically feasible.

\section{Summary Background Data}

The indications for surgical resection for liver metastases from colorectal cancer remain controversial. Several clinical risk factors have been reported to influence survival.

\section{Methods}

Between March 1980 and December 1997, 235 patients underwent hepatic resection for metastatic colorectal cancer. Survival rates and disease-free survival as a function of clinical and pathologic determinants were examined retrospectively with univariate and multivariate analyses. tumor, lymph node metastasis, and multiple nodules were significantly associated with a poor prognosis in both univariate and multivariate analyses. Disease-free survival was significantly influenced by lymph node metastasis, a short interval between treatment of the primary and metastatic tumors, and a high preoperative level of carcinoembryonic antigen. The 10-year survival rate of patients with four or more nodules (29\%) was better than that of patients with two or three nodules (16\%), and similar to that of patients with a solitary lesion (32\%).

\section{Conclusions}

Surgical resection is useful for treating liver metastases from colorectal cancer. Although multiple metastases significantly impaired the prognosis, the life expectancy of patients with four or more nodules mandates removal.

\section{Results}

The overall 3-, 5-, 10-, and 15-year survival rates were 51\%, $38 \%, 26 \%$, and $24 \%$, respectively. The stage of the primary

Although surgical resection is still considered the gold standard in patients with liver metastases from colorectal cancer,

Supported in part by grants-in-aid for Cancer Research from the Ministry of Health and Welfare of Japan.

Correspondence: Masami Minagawa, MD, Dept. of Hepato-Biliary-Pancreatic Surgery, Dept. of Artificial Organ and Transplantation, Graduate School of Medicine, University of Tokyo, 7-3-1, Hongo, Bunkyoku, Tokyo, 113-8655, Japan.

Accepted for publication June 25, 1999. its indications are limited and the resectability rate is reported to be only $25 \% .{ }^{1}$ Moreover, the factors that affect the prognosis remain unclear ${ }^{2-20}$ (Table 1), and these uncertain findings, together with the recent spread of interstitial therapies, ${ }^{21-25}$ have further reduced the indications for surgical resection. However, techniques such as preoperative portal embolization $^{26}$ and intraoperative ultrasonography, ${ }^{27}$ which have been associated with improvements in perioperative patient management, have led to safe hepatic resections with no deaths, 


\begin{tabular}{|c|c|c|c|c|c|c|c|c|c|c|c|c|c|c|c|c|c|c|}
\hline Lead Author & 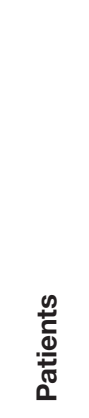 & 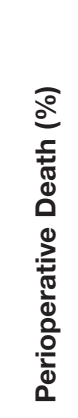 & @্ & હ & 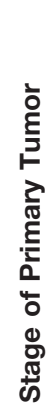 & 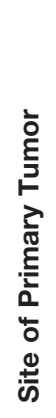 & 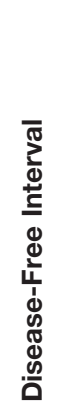 & 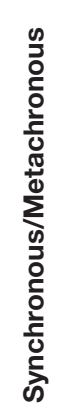 & 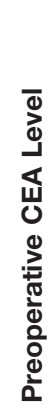 & 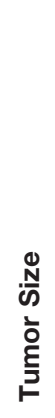 & 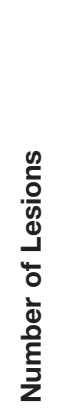 & 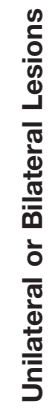 & 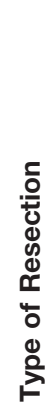 & 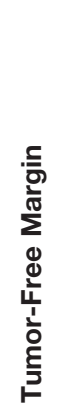 & 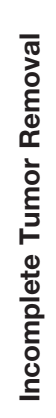 & 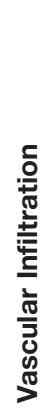 & 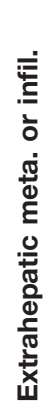 & 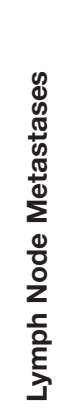 \\
\hline Butler, $1986^{2}$ & 62 & 10 & & - & + & - & - & - & & - & - & - & & & & & & \\
\hline Iwatsuki, $1986^{3}$ & 60 & 0 & - & - & + & & & & & & + & & & + & & & & \\
\hline Reg. Hep. Met., & & & & & & & & & & & & & & & & & & \\
\hline $1988^{4}$ & 859 & - & + & - & + & & + & & - & + & + & - & & - & - & & & \\
\hline Doci, $1991^{5}$ & 100 & 5 & - & - & + & - & & - & - & + & - & - & - & & & & & \\
\hline Gayowski, $1994^{6}$ & 204 & 0 & - & - & - & - & - & & & - & + & + & - & - & + & + & + & + \\
\hline Pedersen, $1994^{7}$ & 66 & 7.6 & - & - & - & & - & & & + & - & & & & + & & + & \\
\hline Scheele, $1995^{1}$ & 469 & 4.4 & - & - & + & - & & + & - & + & - & - & + & - & & & - & \\
\hline Nordlinger, $1996^{8}$ & 1568 & 2.3 & - & - & + & + & + & & & + & + & - & - & + & & & & \\
\hline Wanebo, $1996^{9}$ & 74 & 7 & - & - & - & & - & - & & & - & + & + & & & & & \\
\hline Beckurts, $1997^{10}$ & 126 & 2 & - & - & - & & & + & & & & & - & & + & & & + \\
\hline Jaeck, $1997^{11}$ & 747 & 3.6 & & & + & & - & & - & - & - & - & - & + & & & & \\
\hline Jamison, $1997^{12}$ & 280 & 4 & & & - & & & & & - & - & & - & - & & & + & + \\
\hline Jenkins, $1997^{13}$ & 131 & 3.8 & - & - & & - & & + & & & - & & - & & + & & + & \\
\hline Rees, $1997^{14}$ & 150 & 1 & & & - & & & - & & + & - & - & & + & & & & \\
\hline Taylor, $1997^{15}$ & 123 & 0 & - & - & - & & & - & & - & + & & & & & & & \\
\hline Yasui, $1997^{16}$ & 81 & 2 & & & & & & & & & - & & + & & & - & - & + \\
\hline \multicolumn{19}{|l|}{ Bakalakos, } \\
\hline $1998^{17}$ & 301 & 4 & & & - & & - & & & - & - & + & - & & + & & & \\
\hline Cady, $1998^{18}$ & 244 & 3.7 & & & - & & - & & + & - & + & - & & + & & & & \\
\hline Elias, $1998^{19}$ & 196 & 1.5 & & & & & & & & & - & - & & + & + & & - & \\
\hline Ohlsson, $1998^{20}$ & 111 & 3.6 & & & & & & & + & & & & & & & & + & + \\
\hline Present study & 235 & 0 & - & - & + & - & - & - & - & - & + & - & - & - & & - & - & + \\
\hline \multicolumn{19}{|l|}{ Rate of positivity } \\
\hline (\%) & & & 8 & 0 & 47 & 14 & 20 & 33 & 29 & 43 & 37 & 23 & 25 & 55 & 86 & 33 & 56 & 100 \\
\hline
\end{tabular}

even in patients with cirrhosis, ${ }^{28}$ and have extended the possibility of liver surgery to patients with advanced metastatic tumors. ${ }^{29}$ Therefore, two opposite trends can be recognized: one is toward a less-invasive approach, with broader indications for more conservative therapies such as interstitial treatment, and the other is a more aggressive policy that extends the indications for surgery.

Since 1980, we have applied the same selection criteria to candidates for liver resection, and all of the patients with technically resectable metastases from colorectal cancer actually underwent surgery. In this study, we retrospectively evaluated the long-term results of our series to determine the factors that affected the prognosis, and then tried to clarify the surgical indications.

\section{PATIENTS AND METHODS}

From 1980 to 1997,254 patients with hepatic metastases from colorectal cancer underwent liver resection at the
Department of Surgery, National Cancer Center, Tokyo (1980-1990), the First Department of Surgery, Shinshu University, Matsumoto (1990-1994), and the Department of Hepato-Biliary-Pancreatic Surgery, University of Tokyo, Tokyo (1994-1997). The second author (Dr. Makuuchi) participated in all of these operations.

The selection criteria for surgery were the possibility of an oncologically radical operation and the possibility of preserving at least $40 \%$ of the normal hepatic parenchyma. The total number of hepatic metastases, their unilateral or bilateral presentation, and the existence of extrahepatic metastases were not considered exclusion criteria.

In all patients, the preoperative diagnostic workup included ultrasonography and plain and contrast-enhanced CT to stage the liver involvement, and chest $\mathrm{x}$-ray, chest CT, barium enema, colonoscopy, and bone scintigraphy to assess for extrahepatic disease. Intraoperative bimanual liver palpation and ultrasound were also carried out in all pa- 
tients, and all the resections were ultrasound-guided procedures.

In 19 patients, resections were not considered radical because of gross residual disease within or outside the liver; these patients were excluded from this study. Reasons for nonradical resection included liver involvement judged too extensive to permit complete resection (eight patients), presence of a metastatic pelvic peritoneal extensive implant (three patients), presence of metastasis of Virchow's lymph nodes (one patient), and lung metastasis that was not resectable (seven patients). All of the gross disease was removed in the remaining 235 patients.

One hundred forty-eight patients were men and 87 were women, with a median age of 59.2 years (range 30-80). The primary colorectal tumor was located in the cecum in one patient, in the ascending and transverse colon in 25 and 23 , respectively, in the descending colon in 11 , in the sigmoid colon in 78, and in the rectosigmoid region in 91. In the remaining seven patients, we could not obtain this information because the operation was performed at another hospital. Dukes' staging of the primary colorectal cancer was known in 218 of the 235 patients; it consisted of Dukes' A in 5 patients, Dukes' $\mathrm{B}$ in 50, and Dukes' $\mathrm{C}$ in the remaining 163 . All the primary tumors were adenocarcinomas. The interval between resection of the colorectal primary tumor and hepatic resection ranged from 0 (synchronous resection) to 100 months (mean 11.7 months, median 6 months); synchronous resections were performed in 109 patients. Since portal vein embolization was introduced, ${ }^{26}$ eight patients underwent this procedure before hepatic resection to prevent postoperative liver failure resulting from the need to remove more than $60 \%$ of the hepatic parenchyma in the normal liver and four or more Couinaud segments ${ }^{30}$ in the presence of ICG15 values ranging from $10 \%$ to $20 \%$. $^{31}$

At first hepatectomy, 619 lesions were resected, with a mean number of 2.6 lesions per patient (median 2, range 1-17). One hundred ten patients had solitary hepatic lesions, 45 had two nodules, 27 had three, and 53 had four or more. Regarding these latter patients, 20 had 4 nodules, 11 had 5, 5 had 6, 8 had 7, 2 had 8, and 11,12,13, 15 and 16 lesions were removed in 5 other patients; 17 deposits were resected in 2 patients. These last 53 patients had a total of 338 nodules, with a mean of 6.4 per patient. The maximum diameter of the hepatic nodules was 0.4 to $19 \mathrm{~cm}$ (average $4.5 \mathrm{~cm}$, median 3.9). In 146 patients, the metastasis was unilateral $(62.1 \%)$, whereas 89 patients had bilateral hepatic deposits (37.9\%). Extrahepatic direct invasion was observed in 13 patients; it consisted of overgrowth to the diaphragm in 6 , the omentum in 2 , the porta hepatis in 2 , the pancreas in 1 , the right adrenal gland in 1 , and the inferior vena cava in 1. Seventeen patients had associated distant extrahepatic metastases, which were all removed: three had lung metastasis, and the rest consisted of six cases of localized peritoneal tumor implants, six local recurrences at the site of the primary tumor, and two rib metastases. Lymph node me-
Table 2. TYPE OF SURGICAL PROCEDURES

\begin{tabular}{lr}
\hline \multicolumn{1}{c}{ Type of Resection } & No. of Patients \\
\hline Three or more segments & 50 \\
$\quad$ Left hepatectomy & 16 \\
Extended left hepatectomy & 4 \\
Right hepatectomy & 18 \\
Extended right hepatectomy & 10 \\
Segment 4, 5, and 8 resection & 2 \\
One or two segments & 48 \\
Segment 2 and 3 resection & 20 \\
Segment 5 and 8 resection & 12 \\
Segment 6 and 7 resection & 10 \\
Segment 4 resection & 6 \\
Associated wedge resection & 24 \\
Wedge resection & 137 \\
$\quad$ Single & 71 \\
Multiple & 66 \\
Total & 235 \\
& \\
\hline
\end{tabular}

tastases were found in six patients, and they were also removed at the time of liver resection. Macroscopic vascular invasion and gross bile duct invasion were found in 24 (10.2\%) and 18 patients (7.6\%), respectively.

In accord with Couinaud's anatomical classification of the liver, ${ }^{30}$ the type of resection is shown in Table 2 . One hundred seventy-one patients showed disease relapse: in 98 of them it was in the liver, and 50 underwent further liver resections. The total number of operations was 296 for the 235 patients, with a mean number of 1.3 per patient (median 1 , range 1-4): 185 patients were operated on once, 40 twice, 9 three times, and 1 patient underwent four surgical procedures. Therefore, a total of 753 nodules were removed in one or more liver resections (mean 3.2, median 2, range 1-22). A single nodule was removed in 93 patients 2 were removed in 45,3 in 32,4 in 17, 5 in 15,6 in 7, 7 in 6,8 in 4,9 in 2,10 in 3,11 in 2,12 in 2 , and $13,15,16,17,18$, 20 , and 22 deposits in 1 patient each. The preoperative serum carcinoembryonic antigen (CEA) level (normal range $0-5 \mathrm{ng} / \mathrm{mL}$ ) was 0.1 to $5,711 \mathrm{ng} / \mathrm{mL}$ (average 236, median 26.9).

Overall and disease-free survival analyses were performed for the entire series and on patients grouped as a function of the following factors: sex, age (younger than 60 vs. 60 or older), primary tumor site (cecum and ascending colon, transverse colon, descending colon, sigmoid colon, and rectum), stage (Dukes' A and B, Dukes' C), interval between treatment of the primary tumor and resection of liver metastases ( $<3$ months, 3-24 months, $\geq 24$ months), maximum diameter of the liver lesions $(<2 \mathrm{~cm}, 2-5 \mathrm{~cm}, \geq 5$ $\mathrm{cm}$ ), their number (single, two or three, four or more) and intrahepatic distribution (unilateral or bilateral) at the time of the first operation, extrahepatic direct invasion, vascular and biliary infiltration, distant and lymph node metastases, type of liver resection (three or more segments, one or two 
$(\%)$

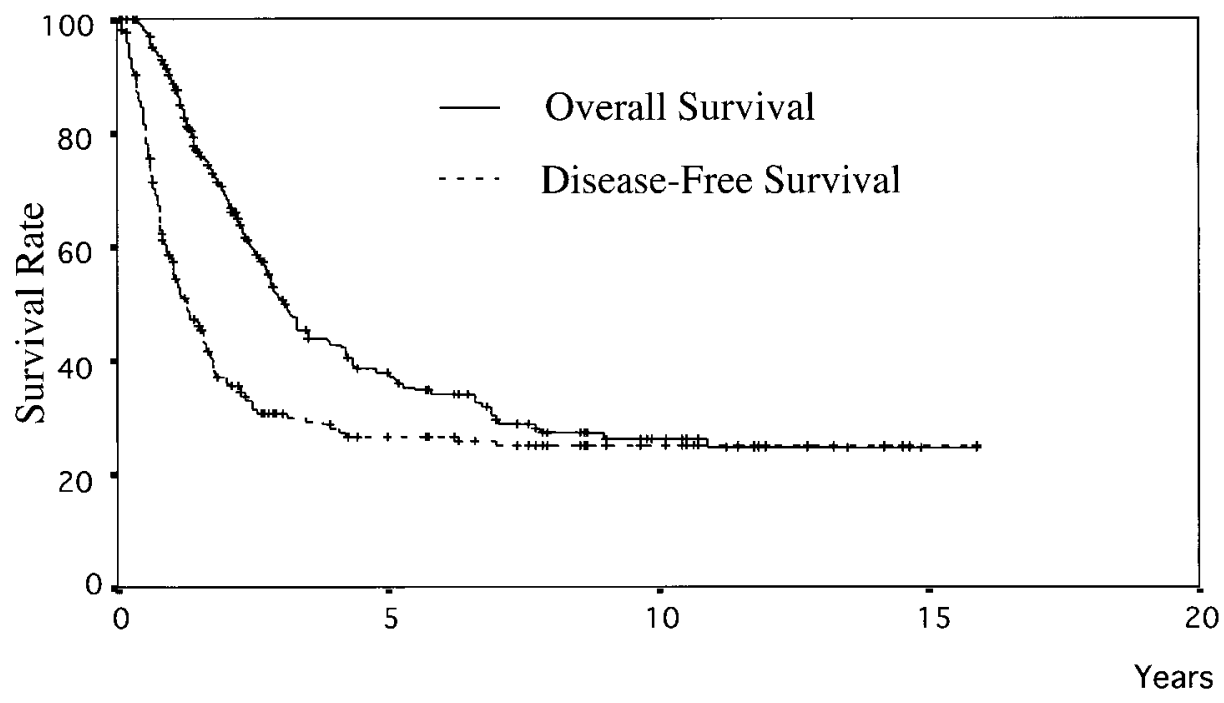

Figure 1. Overall and disease-free survival rates of 235 patients after the first hepatic resection. segments, wedge resection), tumor-free margins $(<1 \mathrm{~cm}$, $\geq 1 \mathrm{~cm}$ ), and preoperative serum CEA level $(<50 \mathrm{ng} / \mathrm{mL}$, $\geq 50 \mathrm{ng} / \mathrm{mL}$ ). For the analysis of long-term survival, we also considered the total number of lesions resected per patient in one or more operations (one, two or three, and four or more). A survival analysis was carried out using the KaplanMeier (product-limit) method, with the date of the hepatic resection as a starting point. Survival curves were compared with the log-rank test. A multivariate stepwise Cox regression analysis was performed to identify significant contributors that were independently associated with death and disease-free survival among those factors that were found significant on univariate analysis. $P \leq .05$ was considered significant.

\section{RESULTS}

The mean follow-up period was 43 months (median 28, range 1-193). There were no deaths in the first 30 days after surgery. The overall survival rate (Fig. 1) and survival calculated according to patient characteristics and the features of the primary and metastatic tumors are shown in Table 3. Gender, age, and the site of the primary tumor were not correlated with patient survival, whereas Dukes' C and an interval between colonic and liver resections of 3 months or less were significantly associated with a poor prognosis (Fig. 2). Patients with a solitary metastasis at the time of surgery had a better prognosis than those with multiple hepatic deposits (Fig. 3). Conversely, no significant differences in long-term survival were found among patients with single nodules and those with four or more lesions: both of these groups showed better 10-year survival rates than patients with two or three metastases (Fig. 4). Table 4 shows the features of the long-term survivors with a total of four or more lesions resected in one or more operations.

No statistically significant differences were observed when survival was evaluated according to the maximum lesion diameter or when comparing patients with unilateral and bilateral multiple nodules. The 17 patients with extrahepatic distant metastases at the time of the operation had a worse survival than those without such metastases, but this difference was not statistically significant. In particular, patients with localized peritoneal seedings had a mean survival of 3.1 years (range 1.2-5.1). The 13 patients with direct extrahepatic invasion did not have a significantly worse long-term survival than the other patients. On univariate analysis, the type of surgical resection did not significantly affect the patient prognosis, whereas the presence of lymph node metastasis at the hepatic hilum or at the celiac trunk at the time of the hepatectomy was significantly associated with worse patient survival. However, macroscopic vascular invasion and bile duct involvement were not significantly correlated with patient survival.

In no patients were the cut liver surfaces involved by residual tumors, and tumor-free margins were not correlated with patient survival. Patients with a preoperative serum CEA level of less than $50 \mathrm{ng} / \mathrm{mL}$ had a significantly better prognosis than those with higher values (Fig. 5).

The five variables that significantly contributed to the life expectancy on univariate analysis were analyzed by the Cox proportional hazard model, and the results are shown in Table 5. Lymph node metastasis, primary tumor stage, and number of metastases were independently associated with patient survival, whereas none of the remaining factors was significant in a multivariate context.

Disease-free survival data were obtained for the 235 patients (see Fig. 1), and Table 6 shows disease-free survival based on patient characteristics and the features of the primary tumor and the liver metastases. Again, Dukes' C primary tumors, an interval of less than 3 months between removal of the colorectal cancer and resection of liver 
Table 3. LONG-TERM SURVIVAL BASED ON PATIENT CHARACTERISTICS AND FEATURES OF PRIMARY AND METASTATIC TUMORS

\begin{tabular}{|c|c|c|c|c|c|c|c|c|c|}
\hline \multirow[b]{2}{*}{ Factor } & \multirow[b]{2}{*}{$\begin{array}{c}\text { No. of } \\
\text { Patients }\end{array}$} & \multicolumn{4}{|c|}{ Overall Survival in Years (\%) } & \multirow[b]{2}{*}{$\begin{array}{l}\text { Mean Survival } \\
\text { (SEM) }\end{array}$} & \multirow[b]{2}{*}{$\begin{array}{l}\text { Median Surviva } \\
\text { (SEM) }\end{array}$} & \multirow{2}{*}{\multicolumn{2}{|c|}{$P$ Value }} \\
\hline & & 3 & 5 & 10 & 15 & & & & \\
\hline Overall & 235 & 51 & 38 & 26 & 24 & $6.1(0.4)$ & $3.1(0.2)$ & & \\
\hline \multicolumn{10}{|l|}{ Age (years) } \\
\hline$<60$ & 115 & 52 & 40 & 33 & 33 & $6.7(0.7)$ & $3.2(0.6)$ & \multirow{2}{*}{\multicolumn{2}{|c|}{ NS }} \\
\hline$\geq 60$ & 120 & 50 & 36 & 19 & $-^{*}$ & $5.2(0.5)$ & $3.0(0.2)$ & & \\
\hline \multicolumn{10}{|l|}{ Gender } \\
\hline Female & 87 & 49 & 37 & 25 & - & $5.5(0.7)$ & $2.9(0.3)$ & \multirow{2}{*}{\multicolumn{2}{|c|}{ NS }} \\
\hline Male & 148 & 52 & 38 & 27 & 27 & $6.3(0.6)$ & $3.1(0.3)$ & & \\
\hline \multicolumn{10}{|l|}{ Primary tumor stage } \\
\hline Dukes' A-B & 55 & 64 & 54 & 41 & - & $8.1(0.9)$ & $7.0(2.2)$ & .0006 & \\
\hline Dukes' C & 163 & 44 & 33 & 21 & 19 & $5.3(0.9)$ & $2.6(0.2)$ & .0000 & NS \\
\hline Unknown & 17 & 58 & 29 & 14 & - & $4.6(1.2)$ & $3.3(1.1)$ & & \\
\hline Primary tumor site & & & & & & & & & \\
\hline Cecum/ascending colon & 25 & 63 & 28 & 28 & - & $5.5(1.2)$ & $3.3(0.1)$ & & \\
\hline Transverse colon & 23 & 42 & 32 & 32 & 32 & $5.8(1.4)$ & $2.8(0.7)$ & & \\
\hline Descending colon & 11 & 62 & 31 & - & - & $3.2(0.7)$ & $3.3(0.5)$ & NS & \\
\hline Sigmoid colon & 78 & 55 & 48 & 31 & - & $6.8(0.7)$ & $4.8(1.4)$ & & \\
\hline Rectum & 91 & 46 & 32 & 22 & - & $5.2(0.6)$ & $2.7(0.3)$ & & \\
\hline Unknown & 7 & 71 & 36 & - & - & $4.0(1.2)$ & $3.2(1.3)$ & & \\
\hline Interval (months) & & & & & & & & & \\
\hline $0-3$ & 106 & 41 & 30 & 22 & 16 & $5.0(0.6)$ & $2.3(0.3)$ & 03 & \\
\hline $4-24$ & 90 & 57 & 44 & 28 & - & $6.5(0.7)$ & $4.2(0.8)$ & & .04 \\
\hline$\geq 25$ & 39 & 64 & 46 & 30 & - & $6.9(1.1)$ & $3.3(1.8)$ & NS & \\
\hline Number of lesions & & & & & & & & & \\
\hline Single & 110 & 63 & 46 & 32 & 32 & $7.3(0.7)$ & $4.3(1.1)$ & 0037.0 & 0017 \\
\hline Multiple & 125 & 40 & 30 & 21 & - & $4.9(0.5)$ & $2.5(0.2)$ & & \\
\hline $2-3$ & 72 & 37 & 29 & 16 & - & $4.4(0.6)$ & $2.3(0.2)$ & & \begin{tabular}{l|l} 
NS \\
\end{tabular} \\
\hline$\geq 4$ & 53 & 46 & 32 & 29 & - & $5.1(0.7)$ & $2.6(0.3)$ & & NS \\
\hline Total resected number & & & & & & & & & \\
\hline 1 & 110 & 63 & 46 & 32 & 32 & $7.3(0.7)$ & $4.3(1.1)$ & & 7 \\
\hline $2-3$ & 77 & 39 & 33 & 19 & - & $4.8(0.7)$ & $2.3(0.2)$ & & .02 \\
\hline$\geq 4$ & 65 & 45 & 30 & 23 & - & $4.7(0.6)$ & $2.8(0.3)$ & NS & \\
\hline Tumor size (cm) & & & & & & & & & \\
\hline$\leq 2$ & 54 & 47 & 35 & 26 & - & $5.7(0.8)$ & $2.8(0.8)$ & & \\
\hline $2.1-5$ & 113 & 54 & 43 & 30 & 26 & $6.6(0.7)$ & $3.3(0.7)$ & NS & \\
\hline$>5$ & 68 & 50 & 33 & 21 & - & $5.3(0.7)$ & $3.0(0.3)$ & & \\
\hline Tumor distribution & & & & & & & & & \\
\hline Unilateral & 40 & 44 & 29 & 21 & - & $4.5(0.9)$ & $2.8(0.4)$ & H & \\
\hline Bilateral & 85 & 39 & 31 & 21 & - & $5.0(0.6)$ & $2.3(0.3)$ & NS & \\
\hline Extrahepatic metastases & & & & & & & & & \\
\hline Negative & 218 & 52 & 39 & 28 & 26 & $6.4(0.5)$ & $3.2(0.3)$ & $\mathrm{NC}$ & \\
\hline Positive & 17 & 41 & 21 & 7 & - & $3.5(0.7)$ & $2.8(0.7)$ & NS & \\
\hline Extrahepatic invasion & & & & & & & & & \\
\hline Negative & 222 & 51 & 39 & 27 & 25 & $6.2(0.5)$ & $3.1(0.4)$ & & \\
\hline Positive & 13 & 54 & 0 & - & - & $2.6(0.2)$ & $3.1(0.5)$ & NS & \\
\hline Lymph node metastases & & & & & & & & & \\
\hline Negative & 229 & 52 & 39 & 27 & 25 & $6.2(0.5)$ & $3.1(0.2)$ & & \\
\hline Positive & 6 & - & - & - & - & $1.2(0.2)$ & $1.2(0.1)$ & .0001 & \\
\hline Vascular invasion & & & & & & & & & \\
\hline Negative & 211 & 50 & 36 & 25 & 23 & $6.0(0.5)$ & $3.0(0.2)$ & $\mathrm{NG}$ & \\
\hline Positive & 24 & 64 & 52 & 44 & - & $7.5(1.4)$ & $5.2(1.7)$ & NS & \\
\hline Biliary tree invasion & & & & & & & & & \\
\hline Negative & 217 & 50 & 38 & 25 & 23 & $6.0(0.5)$ & $3.0(0.2)$ & & \\
\hline Positive & 18 & 65 & 36 & 36 & - & $5.9(1.2)$ & $4.2(1.0)$ & NS & \\
\hline Type of resection & & & & & & & & & \\
\hline Wedge & 137 & 47 & 36 & 26 & 24 & $6.0(0.6)$ & $2.7(0.4)$ & & \\
\hline 1 or 2 segments & 48 & 56 & 40 & 27 & - & $5.5(0.7)$ & $3.1(0.8)$ & NS & \\
\hline 3 or more segments & 50 & 57 & 38 & 24 & - & $5.7(0.9)$ & $3.3(0.4)$ & & \\
\hline Tumor-free margin & & & & & & & & & \\
\hline$<1 \mathrm{~cm}$ & 118 & 57 & 45 & 26 & - & $6.2(0.6)$ & $4.2(0.8)$ & & \\
\hline$\geq 1 \mathrm{~cm}$ & 27 & 58 & 24 & 12 & - & $4.4(0.9)$ & $3.1(0.3)$ & NS & \\
\hline Unknown & 90 & 41 & 32 & 27 & 24 & $5.8(0.7)$ & $2.5(0.3)$ & & \\
\hline Preoperative CEA level (mg/ & & & & & & & & & \\
\hline$<50$ & 130 & 54 & 43 & 32 & - & $6.7(0.6)$ & $3.3(0.6)$ & .0077 & \\
\hline$\geq 50$ & 83 & 42 & 29 & 18 & - & $4.5(0.6)$ & $2.2(0.4)$ & & NS \\
\hline Unknown & 22 & 72 & 40 & 24 & 24 & $6.8(1.5)$ & $4.3(1.2)$ & NS & \\
\hline
\end{tabular}




\section{$(\%)$}

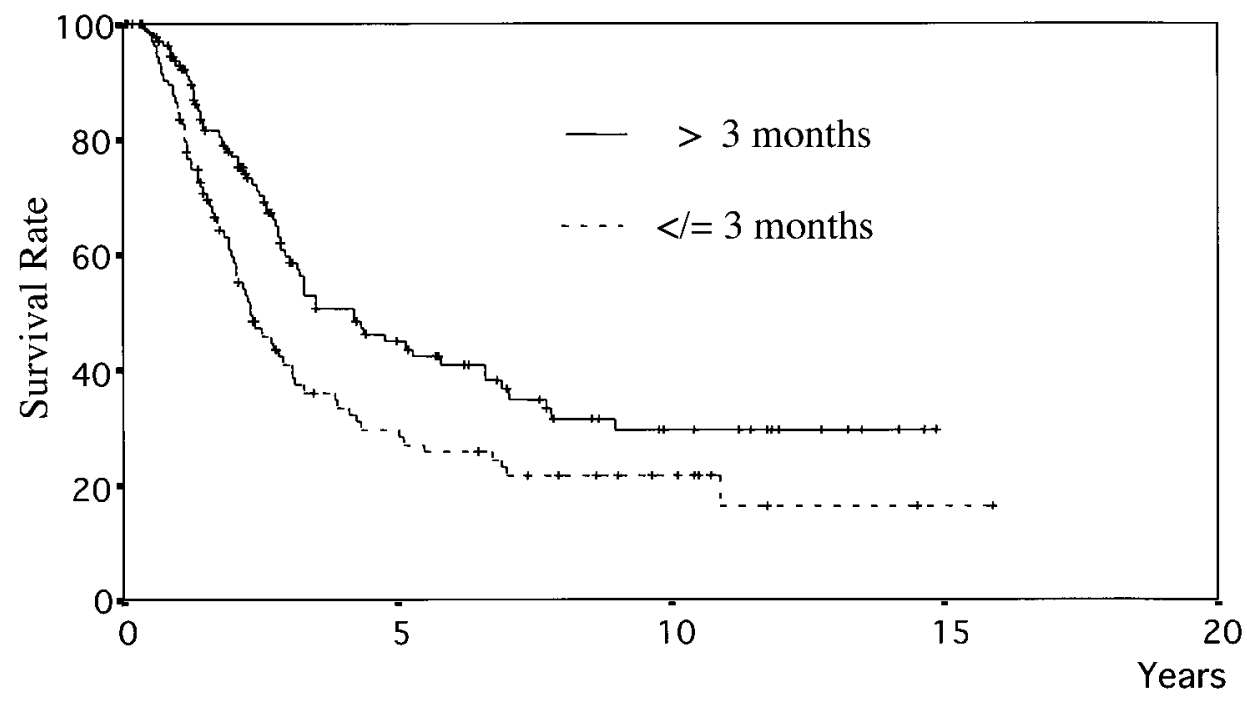

Figure 2. Survival rate according to whether the interval between colorectal resection and hepatectomy was 3 months or less or more than 3 months $(P=.008)$.

metastases, the presence of multiple lesions, and a high preoperative serum CEA level were associated with a significantly worse disease-free survival on univariate analysis. The presence of lymph node metastasis at the hepatic hilum showed a borderline probability value. However, on multivariate analysis, only an interval of less than or equal to 3 months between treatment of the colorectal cancer and liver resection, a high preoperative serum CEA level and the presence of lymph node metastases at the hepatic hilum were significant independent variables (Table 7).

Table 8 shows the survival data for patients grouped according to the presence or absence of recurrence and the life expectancies of those with liver relapse based on whether they underwent further liver resections. Patients with no recurrence showed a $100 \%$ survival rate at 15 years, and patients with liver recurrence who underwent further hepatic resections showed significant survival benefits.

\section{DISCUSSION}

Because $20 \%$ to $30 \%$ of patients with colorectal cancer have synchronous or metachronous liver metastases, their management is a common and important clinical problem. Despite Ewing's ${ }^{32}$ theory that liver metastases and even lung metastases from colorectal cancers can be considered signs of limited dissemination and are therefore suitable for treatment, the natural history of this disease has not been clearly defined by a controlled study. ${ }^{33}$ This lack of knowledge has led to the spread of alternative treatments such as interstitial therapies ${ }^{21-25}$ and also to controversy regarding which factors have a significant impact on patient prognosis after surgery, and which therefore should be considered for patient selection. In reports during the past 15 years, the factors in Table 1 have been reported to impair the prognosis significantly after surgery at an average rate of $37.6 \%{ }^{1-20}$

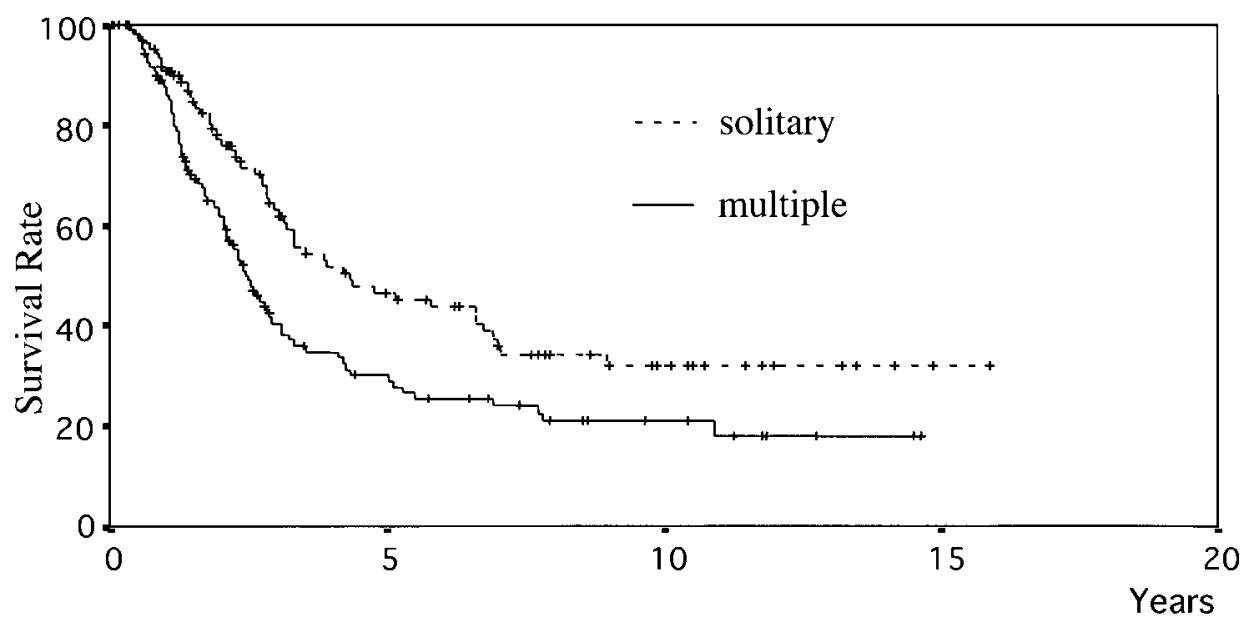

Figure 3. Survival rate according to whether the lesion involved a solitary metastasis or multiple metastases $(P=.003)$. 
Figure 4. Survival rate according to the number of metastases at the first hepatectomy: one nodule versus two or three deposits $(P=$ .001), one versus four or more (NS), and two or three versus four or more (NS).
$(\%)$

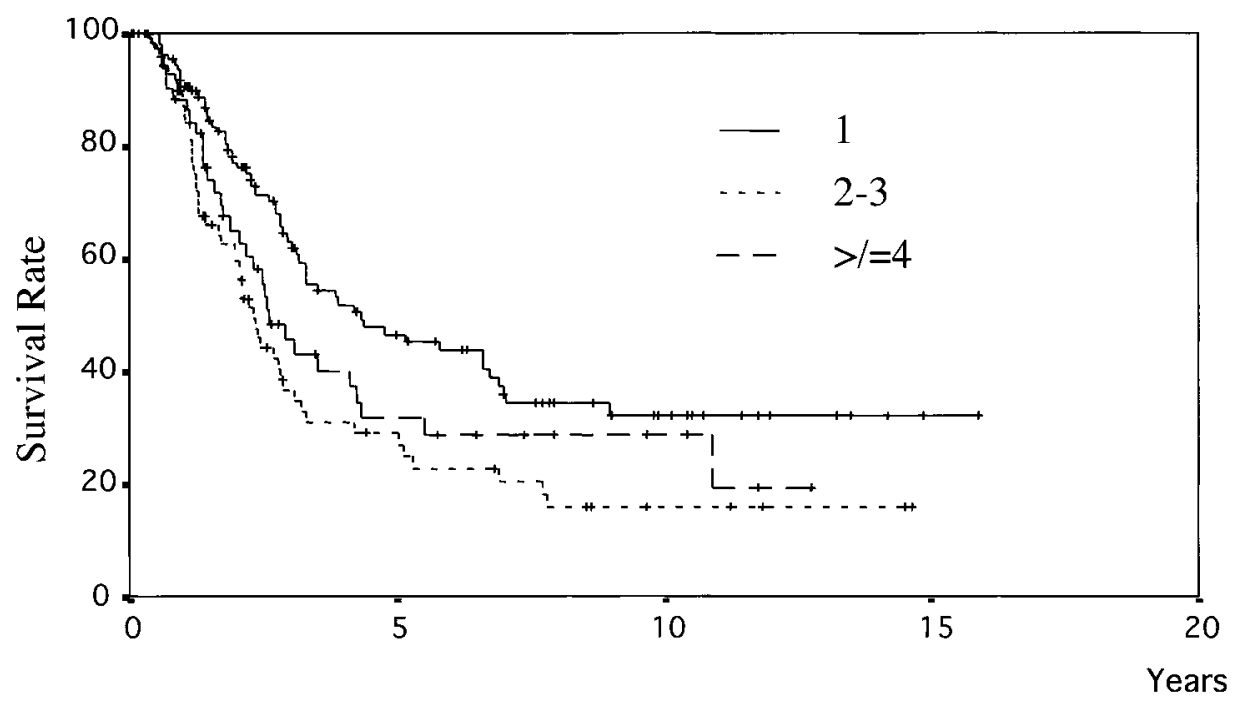

(mean rate of positivity shown in Table 1). Excluding features such as the presence of lymph node metastasis at the hepatic hilum or the celiac trunk, which has consistently been reported to be associated with an impaired prognosis and which should consequently be considered a definitive sign of disseminated disease, and gender, which has never been reported to be a significant prognostic factor, all of the other characteristics were reported to be significant in $8 \%$ to $86 \%$ of the reports considered (rate of positivity in Table 1). These uncertain results have contributed to the spread of other treatments, with the result of excluding patients with single and small nodules from surgery. ${ }^{21-25,34,35}$ This uncertainty also makes it possible to perform surgical treatment in any patient in whom it appears to be technically feasible.
In our experience, excluding patients with the whole liver involved or systemic disease, the routine use of ultrasoundguided resection procedures has eliminated incomplete tumor removal, which $86 \%$ of the reports consider to be associated with a significantly worse outcome (see Table 1). The usefulness of intraoperative ultrasound was confirmed by the finding that the margins of the resected specimen are infiltrated by the tumor in $16 \%$ to $18 \%$ of patients who undergo liver resection without intraoperative ultrasound. ${ }^{36,37}$ Further, complete tumor clearance is probably the main reason for the relatively high percentage $(27.3 \%)$ of patients with no relapse and $100 \%$ survival at the 15 -year follow-up.

Sixty percent of the reports state that a tumor-free margin of less than $1 \mathrm{~cm}$ is a significant prognostic factor, and the

Table 4. FEATURES OF LONG-TERM SURVIVORS (MORE THAN 5 YEARS) AMONG PATIENTS WITH FOUR OR MORE LIVER METASTASES

\begin{tabular}{|c|c|c|c|c|c|c|c|c|c|}
\hline \multirow[b]{2}{*}{ Number } & \multirow[b]{2}{*}{ Age } & \multirow[b]{2}{*}{ Sex } & \multicolumn{4}{|c|}{ Resected Lesions per Operation } & \multirow{2}{*}{$\begin{array}{c}\text { Total } \\
\text { Resected } \\
\text { Lesions }\end{array}$} & \multicolumn{2}{|c|}{ Survival } \\
\hline & & & 1st & 2nd & 3rd & 4th & & Year & Status \\
\hline 1 & 75 & $\mathrm{~F}$ & 5 & & & & 5 & 11 & Dead \\
\hline 2 & 47 & M & 5 & & & & 5 & 13 & Alive \\
\hline 3 & 60 & M & 4 & & & & 4 & 10.5 & Alive \\
\hline 4 & 63 & M & 7 & & & & 7 & 5.5 & Dead \\
\hline 5 & 66 & M & 12 & & & & 12 & 9.5 & Alive \\
\hline 6 & 58 & M & 5 & & & & 5 & 10.5 & Alive \\
\hline 7 & 41 & $\mathrm{~F}$ & 4 & & & & 4 & 12 & Alive \\
\hline 8 & 41 & $\mathrm{~F}$ & 3 & 2 & & & 5 & 7 & Dead \\
\hline 9 & 40 & $M$ & 4 & & & & 4 & 8 & Alive \\
\hline 10 & 48 & $\mathrm{~F}$ & 5 & & & & 5 & 7.5 & Alive \\
\hline 11 & 44 & $M$ & 1 & 8 & & & 9 & 10 & Alive \\
\hline 12 & 55 & $M$ & 2 & 4 & & & 6 & 5 & Dead \\
\hline 13 & 73 & $\mathrm{~F}$ & 4 & 1 & 2 & 1 & 8 & 6.5 & Alive \\
\hline 14 & 52 & $M$ & 13 & & & & 13 & 6 & Alive \\
\hline
\end{tabular}




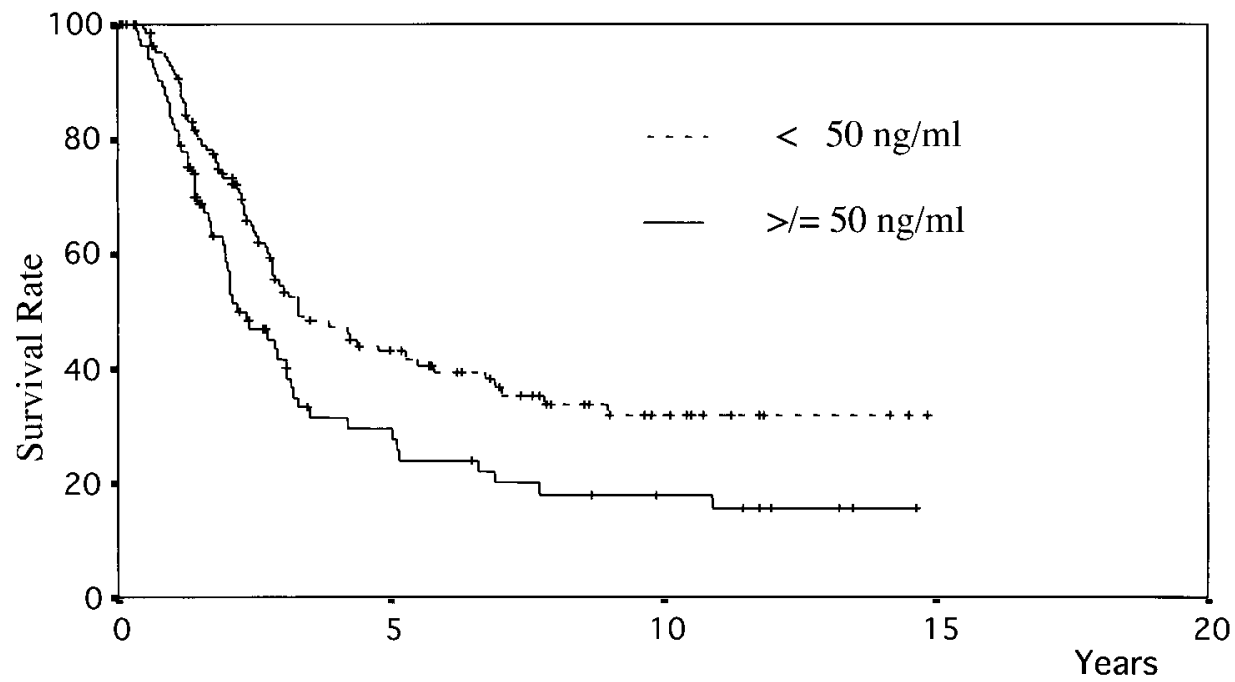

Figure 5. Survival rate according to preoperative level of carcinoembryonic antigen: less than $50 \mathrm{ng} / \mathrm{mL}$ versus $50 \mathrm{ng} / \mathrm{mL}$ or more $(P=.07)$. higher percentage of patients with larger and multiple nodules who do not meet this requirement is considered to be associated with their worse outcome. ${ }^{14,19}$ However, in our experience, this factor did not significantly affect either the prognosis or the disease-free survival. This is consistent with the observations of Yamamoto et al, ${ }^{38}$ who showed that the occurrence of satellite nodules around the main metastatic lesion is rare and therefore wedge resection is justified, even with a tumor-free margin of less than 0.5 to $1 \mathrm{~cm}$ but without exposure of the tumor on the cut surface. Indirect confirmation is given by our results: of all the patients with complete gross tumor removal, there was no

\section{Table 5. RELATIVE RISK OF DEATH WITH COX PROPORTIONAL HAZARD MODEL}

\begin{tabular}{|c|c|c|c|c|}
\hline \multirow[b]{2}{*}{ Variable } & \multirow[b]{2}{*}{ RR } & \multicolumn{3}{|c|}{$\begin{array}{l}\text { Multivariate } 95 \% \\
\text { Confidence Limits }\end{array}$} \\
\hline & & Lower & Upper & $P$ Value \\
\hline Primary tumor stage & & & & .003 \\
\hline Dukes' A-B & 1 & & & \\
\hline Dukes' C & 2.1 & 1.3 & 3.1 & \\
\hline Interval (months) & & & & NS \\
\hline $0-3$ & 1.6 & & & \\
\hline$\geq 4$ & 1 & & & \\
\hline Number of lesions & & & & .008 \\
\hline Single & 1 & & & \\
\hline Multiple & 1.7 & 1.1 & 2.4 & \\
\hline Lymph node metastases & & & & .0002 \\
\hline Negative & 1 & & & \\
\hline Positive & 5.2 & 2.4 & 15.4 & \\
\hline Preoperative CEA level & & & & NS \\
\hline$<50$ & 1 & & & \\
\hline$\geq 50$ & 1.6 & & & \\
\hline
\end{tabular}

difference in survival based on whether the resection was anatomical or not. Three quarters of previous reports agree that the type of resection has no significant influence on patient survival in the case of liver metastases (see Table 1).

Tumor size has been considered an adverse factor in prognosis after surgery, and $43 \%$ of reports examined considered it to be of significant value. ${ }^{1,4,5,7,8,14}$ In our experience, patients with lesions larger than $5 \mathrm{~cm}$ in diameter had life expectancies similar to those with lesions smaller than 2 $\mathrm{cm}$. This result may be related to the fact that tumor clearance was achieved in all patients, whereas among the reports in which tumor size was a significant prognostic factor, larger lesions sometimes did not receive radical treatment. ${ }^{14}$ This could also explain in part why patients with multiple tumors have a worse outcome than those with single metastases. We observed a significant difference in survival when patients were grouped according to the number of lesions, even though all patients had complete tumor clearance. Therefore, the presence of multiple liver metastases seems to be by itself a poor prognostic indicator. This point has been recognized in only $37 \%$ of the examined reports, including our series (see Table 1), and multifocality was not significantly associated with disease-free survival on our multivariate analysis.

The relevance of the number of lesions to patient survival has historically been controversial in the international surgical community. The discussion has focused on the cutoff number of four metastases: for some authors, this number represents the boundary between patients with an acceptable outcome and those with a particularly poor prognosis. ${ }^{6,8,15}$ However, some groups have reported no significant differences in patients with single and multiple lesions. ${ }^{1,2,5,7,9,11-14,16,17,19}$ In some of these reports, there were fewer than four lesions per patient in those with multinodular presentation, ${ }^{2}$ but in others the number of patients with more than four nodules was too small to permit a meaningful evaluation, ${ }^{1,5,9,13,14}$ or the resections were not 
Table 6. DISEASE-FREE SURVIVAL ACCORDING TO PATIENT CHARACTERISTICS AND FEATURES OF PRIMARY AND METASTATIC TUMORS

\begin{tabular}{|c|c|c|c|c|c|c|c|c|c|}
\hline \multirow[b]{2}{*}{ Factor } & \multirow{2}{*}{$\begin{array}{l}\text { No. of } \\
\text { Patients }\end{array}$} & \multicolumn{4}{|c|}{$\begin{array}{c}\text { Disease-Free Survival in } \\
\text { Years (\%) }\end{array}$} & \multirow{2}{*}{$\begin{array}{c}\text { Mean } \\
\text { Survival } \\
\text { (SEM) }\end{array}$} & \multirow{2}{*}{$\begin{array}{l}\text { Median } \\
\text { Survival } \\
\text { (SEM) }\end{array}$} & & \multirow[b]{2}{*}{$P$ Value } \\
\hline & & 3 & 5 & 10 & 15 & & & & \\
\hline Overall & 235 & 30 & 26 & 23 & 23 & $4.7(0.5)$ & $1.3(0.1)$ & & \\
\hline \multicolumn{10}{|l|}{ Age (years) } \\
\hline$<60$ & 115 & 33 & 29 & 26 & 26 & $5.0(0.7)$ & $1.0(0.1)$ & \multirow{2}{*}{ NS } & \\
\hline$\geq 60$ & 120 & 27 & 22 & 20 & - & $4.0(0.6)$ & $1.5(0.1)$ & & \\
\hline \multicolumn{10}{|l|}{ Gender } \\
\hline Female & 87 & 28 & 22 & 20 & - & $4.0(0.7)$ & $1.3(0.2)$ & \multirow{2}{*}{ NS } & \\
\hline Male & 148 & 31 & 28 & 25 & 26 & $5.0(0.6)$ & $1.2(0.2)$ & & \\
\hline \multicolumn{10}{|l|}{ Primary tumor stage } \\
\hline Dukes' $\mathrm{A}-\mathrm{B}^{*}$ & 55 & 37 & 37 & 37 & - & $6.3(0.9)$ & $2.0(0.3)$ & \multirow{2}{*}{.007} & \multirow{3}{*}{$7 \mathrm{NS}$} \\
\hline Dukes' $\mathrm{C}^{\circ}$ & 163 & 28 & 22 & 19 & 19 & $4.0(0.5)$ & $1.0(0.1)$ & & \\
\hline Unknown & 17 & 23 & 23 & 23 & - & $3.6(1.4)$ & $1.3(0.4)$ & NS & \\
\hline Primary tumor site & & & & & & & & & \\
\hline Cecum/ascending colon & 25 & 35 & 28 & 28 & - & $4.5(1.2)$ & $1.3(0.3)]$ & & \\
\hline Transverse colon & 23 & 22 & 22 & 22 & 22 & $4.3(1.4)$ & $1.1(0.9)$ & & \\
\hline Descending colon & 11 & - & - & - & - & $1.2(0.7)$ & $1.0(0.2)$ & NS & \\
\hline Sigmoid colon & 78 & 36 & 30 & 28 & - & $4.9(0.7)$ & $1.6(0.4)$ & & \\
\hline Rectum & 91 & 27 & 23 & 18 & - & $3.8(0.6)$ & $1.2(0.2)$ & & \\
\hline Unknown & 7 & - & - & - & - & $1.5(0.4)$ & 0.8 & & \\
\hline Interval (months) & & & & & & & & & \\
\hline $0-3$ & 106 & 22 & 19 & 19 & 19 & $3.8(0.6)$ & $0.8(0.1)$ & 03 & \\
\hline $4-24$ & 90 & 35 & 28 & 24 & - & $4.7(0.7)$ & $1.5(0.2)$ & .03 & .02 \\
\hline$\geq 25$ & 39 & 38 & 38 & 31 & - & $4.9(0.9)$ & $1.8(0.2)$ & NS & \\
\hline Number of lesions & & & & & & & & & \\
\hline Single & 110 & 41 & 34 & 29 & 29 & $5.9(0.7)$ & $1.8(0.3)$ & 00097 & 70057 \\
\hline Multiple & 125 & 20 & 18 & 18 & - & $3.4(0.5)$ & $0.9(0.1)$ & & 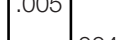 \\
\hline $2-3$ & 72 & 19 & 17 & 17 & - & $3.3(0.7)$ & $1.0(0.2)$ & & .004 \\
\hline$\geq 4$ & 53 & 20 & 20 & 20 & - & $3.1(0.7)$ & $0.8(0.1)$ & & NS \\
\hline Tumor size (cm) & & & & & & & & & \\
\hline$\leq 2$ & 54 & 25 & 20 & 17 & - & $3.5(0.7)$ & $1.0(0.1)$ & & \\
\hline $2.1-5$ & 113 & 33 & 31 & 29 & 29 & $5.5(0.7)$ & $1.5(0.2)$ & NS & \\
\hline$>5$ & 68 & 30 & 22 & 20 & - & $3.6(0.7)$ & $1.2(0.2)$ & & \\
\hline Tumor distribution & & & & & & & & & \\
\hline Unilateral & 40 & 25 & 21 & 21 & - & $3.9(1.1)$ & $1.5(0.6)$ & $\mathrm{NC}$ & \\
\hline Bilateral & 85 & 17 & 17 & 17 & - & $3.2(0.6)$ & $0.8(0.1)$ & NS & \\
\hline Extrahepatic metastases & & & & & & & & & \\
\hline Negative & 218 & 32 & 27 & 26 & 26 & $5.0(0.5)$ & $1.3(0.2)$ & & \\
\hline Positive & 17 & 7 & 7 & - & - & $1.6(0.4)$ & $1.2(0.5)$ & NS & \\
\hline Extrahepatic inavsion & & & & & & & & & \\
\hline Negative & 222 & 31 & 26 & 24 & 24 & $4.8(0.5)$ & $1.2(0.2)$ & NS & \\
\hline Positive & 13 & - & - & - & - & $1.4(0.2)$ & $1.5(0.5)$ & NS & \\
\hline Lymph node metastases & & & & & & & & & \\
\hline Negative & 229 & 30 & 26 & 24 & 24 & $4.8(0.5)$ & $1.3(0.2)$ & 05 & \\
\hline Positive & 6 & - & - & - & - & $0.7(0.2)$ & $0.5(0.1)$ & .05 & \\
\hline Vascular invasion & & & & & & & & & \\
\hline Negative & 211 & 28 & 25 & 22 & 22 & $4.4(0.5)$ & $1.1(0.1)$ & $\mathrm{NS}$ & \\
\hline Positive & 24 & 46 & 38 & 38 & 38 & $6.2(1.4)$ & $2.6(1.2)$ & NS & \\
\hline Biliary tree invasion & & & & & & & & & \\
\hline Negative & 217 & 29 & 25 & 22 & 22 & $4.5(0.5)$ & $1.1(0.2)$ & & \\
\hline Positive & 18 & 39 & 39 & 39 & - & $5.3(1.3)$ & $2.3(1.0)$ & NS & \\
\hline Type of resection & & & & & & & & & \\
\hline Wedge & 137 & 26 & 23 & 21 & 21 & $4.3(0.6)$ & $1.0(0.1)$ & & \\
\hline 1 or 2 segments & 48 & 33 & 27 & 27 & - & $4.1(0.7)$ & $1.6(0.2)$ & NS & \\
\hline 3 or more segments & 50 & 32 & 31 & 23 & - & $4.7(1.1)$ & $1.3(0.2)$ & & \\
\hline Tumor-free margin & & & & & & & & & \\
\hline$<1 \mathrm{~cm}$ & 118 & 30 & 24 & 22 & - & $4.3(0.6)$ & $1.3(0.2)$ & & \\
\hline$\geq 1 \mathrm{~cm}$ & 27 & 27 & 27 & 18 & - & $3.5(1.2)$ & $1.3(0.4)$ & NS & \\
\hline Unknown & 100 & 32 & 30 & 27 & 27 & $5.1(0.8)$ & $1.0(0.1)$ & & \\
\hline Preoperative CEA level (ng/n & & & & & & & & & \\
\hline$<50$ & 130 & 35 & 31 & 30 & - & $5.2(0.6)$ & $1.5(0.2)$ & .002 & \\
\hline$\geq 50$ & 83 & 20 & 16 & 11 & - & $2.8(0.6)$ & $0.8(0.1)$ & .002 & NS \\
\hline Unknown & 22 & 25 & 25 & 25 & 25 & $5.0(2.1)$ & $1.7(0.2)$ & .04 & \\
\hline
\end{tabular}


Table 7. RELATIVE RISK OF DISEASEFREE SURVIVAL WITH COX PROPORTIONAL HAZARD MODEL

\begin{tabular}{|c|c|c|c|c|}
\hline \multirow[b]{2}{*}{ Variable } & \multirow[b]{2}{*}{ RR } & \multicolumn{3}{|c|}{$\begin{array}{l}\text { Multivariate } 95 \% \\
\text { Confidence Limits }\end{array}$} \\
\hline & & Lower & Upper & $P$ Value \\
\hline Primary tumor stage & & & & NS \\
\hline Dukes' A-B & 1 & & & \\
\hline Dukes' C & 1.7 & & & \\
\hline Interval (months) & & & & .006 \\
\hline $0-3$ & 1.6 & 1.2 & 2.3 & \\
\hline$\geq 4$ & 1 & & & \\
\hline Number of lesions & & & & NS \\
\hline Single & 1 & & & \\
\hline Multiple & 1.7 & & & \\
\hline Lymph node metastases & & & & .003 \\
\hline Negative & 1 & & & \\
\hline Positive & 2.4 & 1.6 & 10.3 & \\
\hline Preoperative CEA level & & & & .002 \\
\hline$<50$ & 1 & & & \\
\hline$\geq 50$ & 1.7 & 1.2 & 2.4 & \\
\hline
\end{tabular}

considered radical in most of these patients. ${ }^{1}$ Therefore, if no definitive conclusion has been made either in favor of or against an aggressive approach in patients with more than four lesions, a more conservative approach would appear to be appropriate.

Some of the authors who reported no significant difference in survival between patients with single and multiple nodules consider more than four lesions to be a contraindication for surgery. ${ }^{9}$ In our study, $22.6 \%$ of the patients had more than four lesions, which is the highest rate published to date, and all of these patients underwent radical resection. Although multiple lesions were shown to affect significantly the prognosis on both univariate and multivariate analyses, the long-term life expectancy of patients with four or more lesions did not significantly differ from that of patients with single nodules; it was actually better, although not significantly, than that of patients with two or three lesions at the time of surgical resection (see Table 3 and Fig. 4). An actuarial 10-year life expectancy of $29 \%$ of those with four or more lesions is almost equivalent to that reported for the long-term survival in series with the most favorable situations. This is a remarkable finding, because two patients with 13 and 12 liver metastases at the time of surgery are still alive without recurrence at 6 and almost 10 years of follow-up after surgery (see Table 4).**

Therefore, patients with four or more lesions should undergo liver resection if it is technically feasible. These conclusions should be stressed, considering the poor outcome of similar patients treated with chemotherapy, in whom the survival rate at 2 years is $15 \%$ to $22 \% .{ }^{39,40}$

With regard to unilateral or bilateral tumor distribution, there seems to be agreement that this factor has no prognostic value, although $23 \%$ of the authors examined considered it a significant indicator of poor patient survival. ${ }^{6,9,17}$ In our series, 125 patients had multiple metastases, but no statistically significant differences were observed in the long-term or disease-free survival of patients with unilateral or bilateral presentation. This supports our approach of removing all lesions regardless of their distribution.

Extrahepatic infiltration or metastasis does not significantly impair the prognosis if appropriately treated with surgery. The life expectancy of our 17 patients with extrahepatic disease was not significantly worse than that of the remaining patients, and two of them are still alive at 3 and 11 years after the first treatment. These results may not be achievable with other treatment modalities ${ }^{41}$ confirming the significant improvement in prognosis that can be obtained with extensive resections. Combined liver and lung resection is widely accepted to be effective in patients with hepatic and pulmonary metastatic lesions from colorectal cancer. ${ }^{42-46}$ Sugarbaker et $\mathrm{al}^{47}$ reported their results with cytoreductive surgery and intraperitoneal chemotherapy in patients with localized peritoneal seeding. In our six patients with localized peritoneal seeding, we observed some survival benefit. Therefore, complete removal of the gross tumor should not be avoided in these circumstances.

Our findings and those reported by Yasui et $\mathrm{al}^{16}$ show that if radical removal of the tumor is possible, even the pres-

Table 8. LONG-TERM SURVIVAL ACCORDING TO PRESENCE AND TREATMENT OF RECURRENCE

\begin{tabular}{|c|c|c|c|c|c|c|c|c|}
\hline \multirow[b]{2}{*}{ Factor } & \multirow{2}{*}{$\begin{array}{l}\text { No. of } \\
\text { Patients }\end{array}$} & \multicolumn{4}{|c|}{ Overall Survival in Years (\%) } & \multirow{2}{*}{$\begin{array}{c}\text { Mean } \\
\text { Survival } \\
\text { (SE) }\end{array}$} & \multirow{2}{*}{$\begin{array}{c}\text { Median } \\
\text { Survival } \\
\text { (SE) }\end{array}$} & \multirow[b]{2}{*}{$P$ Value } \\
\hline & & 3 & 5 & 10 & 15 & & & \\
\hline Presence of recurrence & & & & & & & & $<.00001$ \\
\hline No & 64 & 100 & 100 & 100 & 100 & $6.2(0.6)$ & $5.7(0.1)$ & \\
\hline Yes & 171 & 36 & 20 & 6 & 0 & $3.3(0.2)$ & $2.3(0.2)$ & \\
\hline \multicolumn{9}{|l|}{ Resection } \\
\hline No & 48 & 2 & 0 & - & - & $1.2(0.1)$ & $1.1(0.1)$ & $<.00001$ \\
\hline Yes & 50 & 34 & 30 & 12 & - & $3.2(0.6)$ & $1.9(0.1)$ & \\
\hline
\end{tabular}


ence of biliary and vascular tumor infiltration should not exclude patients from surgery. Only Gayowski et $\mathrm{al}^{6}$ mentioned that this finding significantly impairs outcome. The new opportunities provided by surgical techniques involving vascular reconstruction, using autologous vein grafts ${ }^{48}$ and preoperative portal vein embolization, to improve the functional reserve of the remnant liver ${ }^{29,31}$ permit safe and radical resection with no significant impairment of life expectancy or disease-free survival compared with other patients.

Among the remaining prognostic indicators considered, age ${ }^{49,50}$ and primary tumor site have been reported to affect the prognosis significantly in 1 of $11^{4}$ and 1 of 7 studies, ${ }^{8}$ respectively. Other factors, such as primary tumor stage, disease-free interval between treatment of the primary tumor and liver resection, synchronicity of the liver lesions, and the preoperative serum CEA level, have been reported to be significant prognostic factors in $20 \%$ to $47 \%$ of the series examined, and the interval between treatment of the primary tumor and liver metastases and the preoperative serum CEA level were independent significant variables that influenced disease-free survival. At any rate, their respective values in the presence of treatable liver metastases should not discourage the performance of radical hepatectomy.

Hepatectomy should also be considered for postsurgical recurrence: we observed a significant improvement in life expectancy in the treated patients compared with those in whom, because of disseminated disease or patient refusal, further resections were not carried out (see Table 8). This policy has been widely confirmed in the literature. ${ }^{51-60}$ Despite the fear of an increased risk of death with repeated resection, several reports and the present series have demonstrated that multiple resections can be carried out safely, with no perioperative deaths. ${ }^{51-53,55,58,60}$ Further, our experience shows that repeated resections for a multinodular pattern, even if it occurs as recurrence, improve the patient's survival, with a nonnegligible incidence of long-term survivors (see Tables 3 and 4). The possibility that each metastatic recurrence arises from the primary tumor and that these new metastatic foci could have the same prognostic indicators as the first episode should support a policy analogous to that adopted for the first liver metastasis.

By adopting an oncologically aggressive policy while taking extreme care to preserve the liver's functional reserve with the aid of intraoperative ultrasound guidance and with the possibility of inducing hypertrophy of the remnant liver with portal vein embolization, only $3 \%$ of the overall series of 254 patients who underwent surgery for hepatic metastases from colorectal cancer could not undergo radical treatment because of extensive tumor involvement of the liver. Complete tumor removal could be achieved in $92.5 \%$ of the patients, despite the high rate of lesions larger than 5 $\mathrm{cm}$ in diameter $(28.9 \%)$, more than four lesions $(22.6 \%)$, bilateral deposits $(37.9 \%)$, extrahepatic invasion or metastasis $(12.8 \%)$, and vascular or biliary infiltration $(17.8 \%)$. These last features did not significantly influence disease- free survival on multivariate analysis, and their role in determining liver relapse is at best uncertain, as confirmed by their uncertain roles as prognostic indicators in this and other reports. $^{1-20}$

The adequacy of other prognostic indicators such as DNA flow cytometry is also controversial: some recent reports have supported its usefulness, ${ }^{61,62}$ but others have found it to be of little value. ${ }^{63,64}$ These heterogeneous results may be due to differences in the methods used and the heterogeneity of DNA ploidy between primary and liver metastases. ${ }^{65}$ Because of this uncertainty, the identification of patients who could have a lower risk of disease relapse (which in our experience accounted for $27.3 \%$ of all patients and showed $100 \%$ actuarial survival at 15 years) becomes even more unpredictable. Considering the safety of liver surgery, ${ }^{28}$ as demonstrated in this series with no deaths, and its benefits in terms of long-term survival, these results suggest that almost no limitations on indications for surgical treatment, if technically feasible, are warranted.

As with all of the other reports considered here, the present study consisted of a retrospective evaluation covering a long duration, and some biases should be expected. Nevertheless, new techniques, such as portal vein embolization, have extended the indications for surgery, with the inclusion of patients with more advanced disease. Thus, this point could only have worsened the long-term results.

In conclusion, the indications for liver resection for metastases from colorectal cancer are currently determined by the technical feasibility of the treatment, and therefore essentially by the experience of the surgeons. Therefore, a specific scientific background and adequate training in hepatic surgery, including the ability to perform intraoperative ultrasound and portal vein embolization, are mandatory for performing safe and effective treatment.

\section{References}

1. Scheele J, Stang R, Altendorf-Hofmann A, Paul M. Resection of colorectal liver metastases. World J Surg 1995; 19(1):59-71.

2. Butler J, Attiyeh FF, Daly JM. Hepatic resection for metastasis of the colon and rectum. Surg Gynecol Obstet 1986; 162:109-113.

3. Iwatsuki S, Esquivel CO, Gordon RD, Starzl TE. Liver resection for metastatic colorectal cancer. Surgery 1986; 100:804-809.

4. Registry of hepatic metastasis. Resection of the liver for colorectal carcinoma metastases: a multi-institutional study of indications for resection. Surgery 1988; 103:278-288.

5. Doci R, Gennari L, Bignami P, et al. One hundred patients with hepatic metastases from colorectal cancer treated by resection: analysis of prognostic determinants. Br J Surg 1991; 78:797-801.

6. Gayowski TJ, Iwatsuki S, Madariaga JR, et al. Experience in hepatic resection for metastatic colorectal cancer: analysis of clinical and pathologic risk factors. Surgery 1994; 116:703-710.

7. Pedersen IK, Burcharth F, Roikjær O, Baden H. Resection of liver metastases from colorectal cancer. Indications and results. Dis Colon Rectum 1994; 37:1078-1082.

8. Nordlinger B, Guiguet M, Vaillant JC, et al. Surgical resection of colorectal carcinoma metastases of the liver. A prognostic scoring system to improve case selection, based on 1568 patients. Cancer 1996; 77:1254-1262. 
9. Wanebo HJ, Chu QD, Vezeridis MP, Soderberg C. Patient selection for hepatic resection of colorectal metastases. Arch Surg 1996; 131: 322-329.

10. Beckurts KT, Hölscher AH, Thorban S, et al. Significance of lymph node involvement at the hepatic hilum in the resection of colorectal liver metastases. Br J Surg 1997; 84:1081-1084.

11. Jaeck D, Bachellier P, Guiguet $M$, et al. Long-term survival following resection of colorectal hepatic metastases. Association Française de Chirurgie. Br J Surg 1997; 84:977-980.

12. Jamison RL, Donohue JH, Nagorney DM, et al. Hepatic resections for metastatic colorectal cancer. Results in cure for some patients. Arch Surg 1997; 132:505-511.

13. Jenkins LT, Millikan KW, Bines SD, et al. Hepatic resection for metastatic colorectal cancer. Am Surg 1997; 63:605-610.

14. Rees M, Plant G, Bygrave S. Late results justify resection for multiple hepatic metastases from colorectal cancer. Br J Surg 1997; 84:11361140 .

15. Taylor M, Forster J, Langer B, et al. A study of prognostic factors for hepatic resection for colorectal metastases. Am J Surg 1997; 173:467471.

16. Yasui K, Hirai T, Kato T, et al. A new macroscopic classification predicts prognosis for patient with liver metastasis from colorectal cancer. Ann Surg 1997; 226:582-586.

17. Bakalakos EA, Kim JA, Young DC, Martin EW Jr. Determinants of survival following hepatic resection for metastatic colorectal cancer. World J Surg 1998; 22:399-404.

18. Cady B, Jenkins RL, Steele GD Jr, et al. Surgical margin in hepatic resection for colorectal metastasis: a critical and improvable determinant of outcome. Ann Surg 1998; 227:566-571.

19. Elias D, Cavalcanti A, Sabourin JC, et al. Results of 136 curative hepatectomies with a safety margin of less than $10 \mathrm{~mm}$ for colorectal metastases. J Surg Oncol 1998; 69(2):88-93.

20. Ohlsson B, Stenram U, Tranberg KG. Resection of colorectal metastases: 25-year experience. World J Surg 1998; 22:268-276.

21. Solbiati L, Goldberg SN, Ierace T, et al. Hepatic metastases: percutaneous radiofrequency ablation with cooled-tip electrodes. Radiology 1997; 205:367-373.

22. Adam R, Majno P, Castaing D, et al. Treatment of irresectable liver tumors by percutaneous cryosurgery. Br J Surg 1998; 85:1493-1494.

23. Ianniti DA, Heniford BT, Hale J, et al. Laparoscopic cryoablation of hepatic metastases. Arch Surg 1998; 133:1011-1015.

24. Seifert JK, Morris DL. Prognostic factors after cryotherapy for hepatic metastases from colorectal cancer. Ann Surg 1998; 228:201-208.

25. Shuder G, Pistorius G, Schneider G, Feifel F. Preliminary experience with percutaneous cryotherapy of liver tumors. Br J Surg 1998; 85: $1210-1211$.

26. Makuuchi M, Thai BL, Takayasu K, et al. Preoperative portal embolization to increase safety of major hepatectomy for hilar bile duct carcinoma: a preliminary report. Surgery 1990; 107:521-527.

27. Makuuchi M, Takayama T, Kosuge T, et al. The value of ultrasonography for hepatic surgery. Hepato-Gastroenterology 1991; 38(1):64-70.

28. Torzilli G, Makuuchi M, Inoue K, et al. No-mortality liver resection for hepatocellular carcinoma in cirrhotic and non-cirrhotic patients: is there a way? A prospective analysis of our approach. Arch Surg 1999; 134:984-992.

29. Kawasaki S, Makuuchi M, Kakazu T. Resection for multiple metastatic liver tumors after portal embolization. Surgery 1994; 115:674677.

30. Couinaud C. Le Foie, Etude Anatomiques et Chirurgicales. Paris: Masson; 1957.

31. Kubota K, Makuuchi M, Kusaka K, et al. Measurement of liver volume and hepatic functional reserve as a guide to decision-making in resectional surgery for hepatic tumors. Hepatology 1997; 26:1176-1181.

32. Ewing J. Neoplastic Disease: A Treatise on Tumors. Philadelphia: WB Saunders; 1928.
33. Stangl R, Altendorf-Hofmann A, Charnley R, Scheele J. Factors influencing the natural history of colorectal liver. Lancet 1994; 343 : 1405-1410.

34. Mazziotti A, Grazi GL, Gardini A, et al. An appraisal of percutaneous treatment of liver metastases. Liver Transpl Surg 1998; 4:271-275.

35. Hewitt PM, Dwerryhouse SJ, Zhao J, Morris DL. Multiple bilobar liver metastases: cryotherapy for residual lesions after liver resection. J Surg Oncol 1998; 67(2):112-116.

36. Lau WY, Leung KL, Lee TW, et al. Ultrasonography during liver resection for hepatocellular carcinoma. Br J Surg 1993; 80:493-494.

37. Lai ECS, Ng IOL, Ng MMT, et al. Long-term results of resection for large hepatocellular carcinoma: a multivariate analysis of clinicopathological features. Hepatology 1990; 11:815-818.

38. Yamamoto J, Sugihara K, Kosuge T, et al. Pathological support for limited hepatectomy in the treatment of liver metastases from colorectal cancer. Ann Surg 1995; 221:74-78.

39. Kemeny N, Daly J, Reichman B, et al. Intrahepatic or systemic infusion of fluorodeoxyuridine in patients with liver metastases from colorectal carcinoma. Ann Intern Med 1987; 107:459-465.

40. Chang A, Schneider PD, Sugarbaker PH, Simpson C. A prospective randomized trial of regional versus systemic continuous 5-fluorodeoxyuridine chemotherapy in the treatment of colorectal liver metastases. Ann Surg 1987; 206:685-693.

41. Ballantyne GH, Quin J. Surgical treatment of liver metastases in patients with colorectal cancer. Cancer 1993; 71(Suppl 12):42524266.

42. Ambiru S, Miyazaki M, Ito H, et al. Resection of hepatic and pulmonary metastases in patients with colorectal carcinoma. Cancer 1998; 82:274-278.

43. Murata S, Moriya Y, Akasu T, et al. Resection of both hepatic and pulmonary metastases in patients with colorectal carcinoma. Cancer 1998; 83:1086-1093.

44. Regnard JF, Grunenwald D, Spaggiari L, et al. Surgical treatment of hepatic and pulmonary metastases from colorectal cancers. Ann Thorac Surg 1998; 66(1):214-218.

45. Spaggiari L, Grunenwald D, Regnard JF. Resection of hepatic and pulmonary metastases in patients with colorectal carcinoma. Cancer 1998; 83:1049-1051.

46. Robinson BJ, Rice TW, Strong SA, et al. Is resection of pulmonary and hepatic metastases warranted in patients with colorectal cancer? J Thorac Cardiovasc Surg 1999; 117(1):66-75.

47. Sugarbaker PH, Schellinx ME, Chang D, et al. Peritoneal carcinomatosis from adenocarcinoma of the colon. World J Surg 1996; 20:585-591.

48. Takayama T, Nakatsuka T, Yamamoto J, et al. Re-reconstruction of a single remnant hepatic vein. Br J Surg 1996; 83:762-763.

49. Koperna T, Kisser M, Schulz F. Hepatic resection in the elderly. World J Surg 1998; 22:406-412.

50. Fong Y, Brennan MF, Cohen AM, et al. Liver resection in the elderly. Br J Surg 1997; 84:1386-1390.

51. Stone MD, Cady B, Jenkins RL, et al. Surgical therapy for recurrent liver metastases from colorectal cancer. Arch Surg 1990; 125:718-721.

52. Fong Y, Blumgart LH, Cohen A, et al. Repeat hepatic resections for metastatic colorectal cancer. Ann Surg 1994; 220:657-662.

53. Nordlinger B, Vaillant JC, Guiguet M, et al. Survival benefit of repeat liver resections for recurrent colorectal metastases: 143 cases. Association Française de Chirurgie. J Clin Oncol 1994; 12:1491-1496.

54. Que FG, Nagorney DM. Resection of recurrent colorectal metastases to the liver. Br J Surg 1994; 81:255-258.

55. Fernandez-Trigo V, Shamsa F, Sugarbaker PH. Repeat liver resections from colorectal metastasis. Repeat Hepatic Metastases Registry. Surgery $1995 ; 117: 296-304$.

56. Pinson CW, Wright JK, Chapman WC, et al. Repeat hepatic surgery for colorectal cancer metastasis to the liver. Ann Surg 1996; 223:765-773.

57. Wanebo HJ, Chu QD, Avradopoulos KA, Vezeridis MP. Current perspectives on repeat hepatic resection for colorectal carcinoma: a review. Surgery 1996; 119:361-371. 
58. Adam R, Bismuth $\mathrm{H}$, Castaing $\mathrm{D}$, et al. Repeat hepatectomy for colorectal liver metastases. Ann Surg 1997; 225:51-60.

59. Neelman N, Andersson R. Repeated liver resection for recurrent liver cancer. Br J Surg 1996; 83:893-901.

60. Tuttle TM, Curley SA, Roh MS. Repeat hepatic resection as effective treatment of colorectal liver metastases. Ann Surg Oncol 1997; 4(2): 125-130.

61. Costa A, Doci R, Mochen C, et al. Cell proliferation-related markers in colorectal liver metastases: correlation with patient's prognosis. J Clin Oncol 1997; 15:2008-2014.
62. Yamamoto T, Matsumoto K, Iriyama K. Prognostic significance of the DNA index in a colorectal cancer. Surg Today 1998; 28:792-796.

63. Mazzei T, Tonelli F, Mini E, et al. Flow cytometric analysis of DNA ploidy and cell proliferation activity in colorectal carcinoma. Anticancer Res 1995; 15:2247-2253.

64. Tang R, Ho YS, You YT, et al. Prognostic significance of DNA flow cytometric and histopathologic parameters of colorectal cancer. Cancer 1995; 76:1724-1730.

65. Tomoda H, Inoue T. Flow cytometric analysis of the DNA content and metastatic lesions of colorectal cancer. J Surg Oncol 1995; 59(2):101-104. 